\title{
Chapter 4 \\ Limits and Their Vagueness: The Case of Paintings and Photographs
}

\begin{abstract}
This Chapter explores limits between different kinds of works of art, with a focus on painting and photography. I discuss the nature of photography in detail, as well as several borderline cases of photographs, and I argue for the claim that there is an irremediably vague boundary between photographs and (digital) paintings-as opposed to a sharp limit between two different types of images.
\end{abstract}

\subsection{On Photographs and Other Images}

$\S 1$. Chapters 2 and 3 were about extending the limits of what counts as art. The discussion there was centrally focused on the role our different perceptual modalities play. En passant, in Chap. 2, I also shortly discussed two famous borderline cases or artworks, namely, Marcel Duchamp's ready-mades and John Cage's composition "4'33". In this Chapter, I want to explore another type of limits, namely limits there are between different kinds of works of art. My focus will be painting and photography. In fact, photographs have been denied the status of artworks, and I will have something to say about (that is, against) such a view. Thus, I will be interested in the differences between hand-made paintings and photographs, while having in mind that the general context of this discussion can be seen as a contribution to the debate about whether photographs are artworks or not—as opposed to paintings. Indeed, even to articulate this question, one needs to be able to make a distinction between photographs and non-photographs. Kendall Walton thinks that "There is a sharp break, a difference of kind, between painting and photography" (Walton 1984, p. 252). I will argue for the opposite claim: the boundary between photographs and other types of pictures such as paintings is an irreducibly vague one. Furthermore, as we shall see, the differences between photographs and paintings are such that nothing prevents photographs from being artworks.

In a sense, this Chapter is then about what counts as a photograph and what does not. One way in which this question arises stems from new technologies that keep changing our way of producing photographs, such as digital photography, which not only has now widely replaced traditional film photography but also challenges the very limits of what we count as a photograph. I shall discuss below at some length 
different aspects of digital photography, and I will also discuss the case of Light Field cameras (Plenoptic cameras) - indeed, the photographs produced by a Light Field camera can be re-focused after the photograph has been taken, which harbours many interesting consequences with regard to the resulting image and the way we interact with it.

But of course, the initial question also arises in the case of traditional film photography as well as 'traditional' digital photography. The question amounts to asking about what the essential features of photographs are-in short, what their nature is. To answer this question, I shall examine in what follows some 'borderline cases' of photography, thus trying to determine the 'limits' of what counts as a photograph and what does not. In the process, several discriminating criteria and essential features of photographs will be established.

$\S 2$. Before venturing into the discussion of the vague and controversial limits of borderline cases of photographs, let us agree on two uncontroversial paradigmatic cases of two kinds of images which definitely do count as photographs (all photographs used in this book can be found in colour and higher resolution here: https://www.jiribenovsky.org/thelimitsofart):

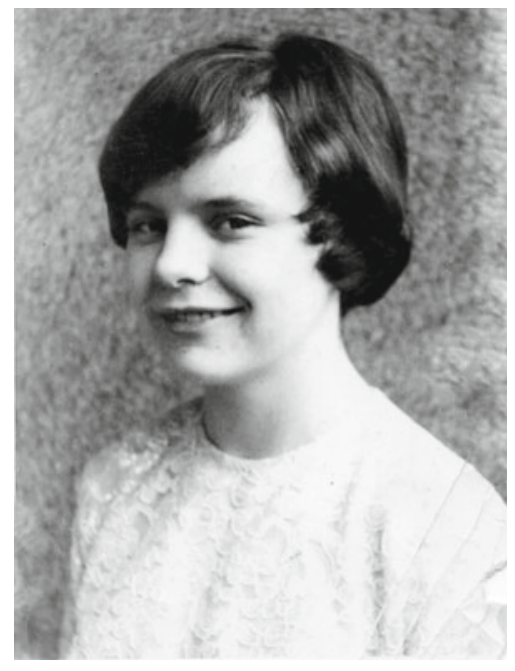

Photo 1 Film photography 


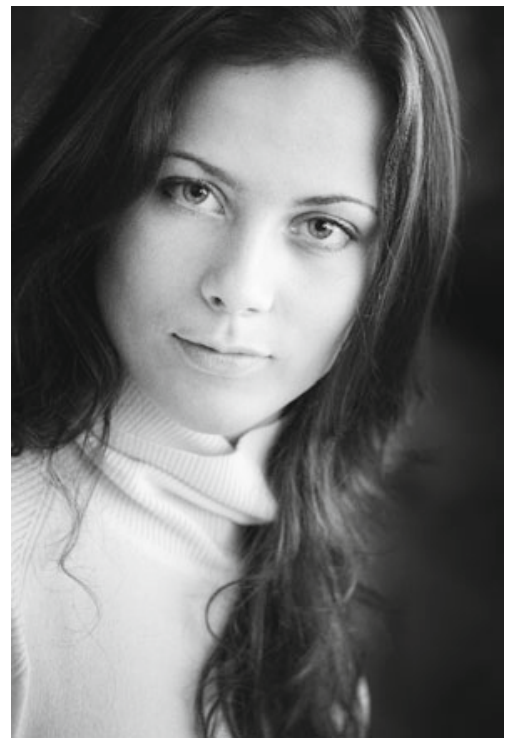

Photo 2 Digital photography

The first photograph was made using a traditional film technology (a film camera, an enlarger, a developer, a stop bath, a fixer, ...) and then scanned in order to be reprinted here for the purposes of this book, while the second was taken with a digital camera and (post)processed accordingly (using software, a computer screen, ...) before being reprinted here.

While there are many significant differences between the two photographs and between the ways they have been created, one thing, I hope, is quite clear: both of these images are photographs. One who would deny this would be implausibly denying the obvious. Any claim, I submit without argument, that would deny that one or both of these images are photographs would exhibit a conception of photography far too restricted and constrained to be true to any artistic, philosophical, or common sense notion of photography. (I shall discuss Roger Scruton's notion of "ideal photography" in II. $\$ 1$ below.)

Thus, my first (and I hope entirely trivial) claim about the nature of photographs is that both traditional film-made photographs and digital photographs are photographs; more precisely, that no particular process of production (digital, chemical, or other) is such that it is the only way of producing photographs. That is, photographs are not in general essentially produced in a particular way.

The way digital photographs are produced actually mirrors the way traditional film photographs are made. 
Fig. 4.1 Film photography

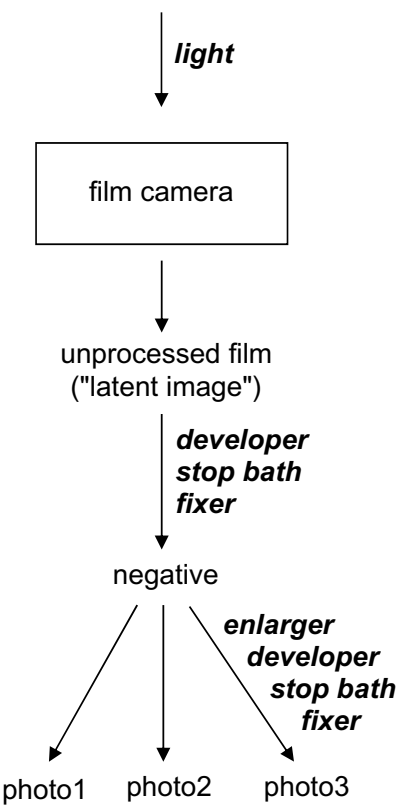

Fig. 4.2 Digital photography

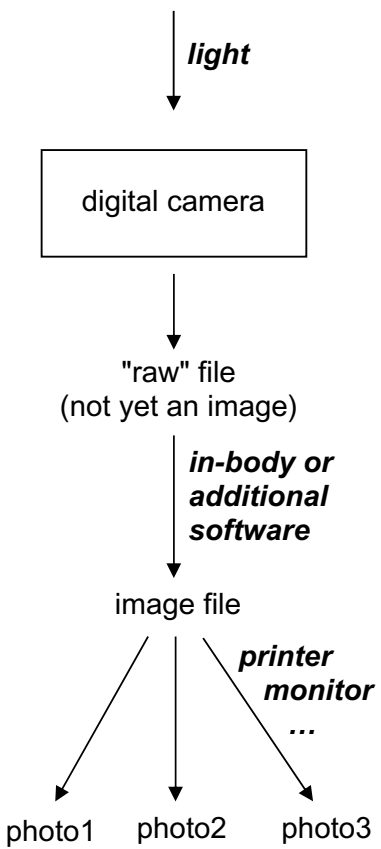


A photograph is a result of a whole process of production, with intermediate stages, and while the nature of these stages is different in traditional photography and digital photography, the overall principles are very similar with stages that play the same (or very similar) role, in a different way. Now, one significant (practical) difference between the two processes of production is the easiness with which digital photographs can be altered by using appropriate software, at early stages of production (before the photograph is created) and/or later in post-processing. Photo 2 above, for instance, has been digitally manipulated during the process of production, both when developing the RAW file and when adjusting the image file in order to produce the final result - light has been improved, skin defects removed, eyes brightened, and so on (follow the permalink mentioned above for a high resolution colour image). But if the image has been "tampered with", one could ask (and one often does ask), does it still count as a photograph? Are digitally modified photographic images still photographs, or are they some sort of 'digital pictures based on a photograph', or not even that?

In the next section, I shall defend the claim that not only such digital pictures are photographs, but that digital manipulation is in fact a necessary step in the process of production of digital photographs.

\subsection{Digital Manipulation}

$\S 1$. Digital manipulation is an essential and necessary feature of the process of production of digital photographs_-very much in the same sense in which chemical manipulation is essential and necessary to traditional film photography. Rejecting these claims would lead one to an implausibly strong conception of photography, where virtually nothing would count as a photograph. Roger Scruton seems to make such a strong claim when he says that "actual photography is the result of the attempt to pollute the ideal of [the photographer's] craft with the aims and methods of painting" (Scruton 1981, p. 578). As far as I understand his claim, Scruton means to say that we have a notion of what an ideal photograph would/should be (namely, an image created in a purely mechanical and causally closed manner, where no chemical or digital or other human manipulation would play any part (more on this below)), but that actual photography does not fit this standard and consequently actual photographs are not really photographs.

Perhaps it is a terminological issue to decide whether actual photographs can be properly called photographs or not, but perhaps it is an issue concerning the very plausibility and relevance of Scruton's claim-indeed, when talking about "ideal" photographs, he just seems to be talking about something entirely different than what most of us take to be photographs. For myself, I have to say I am interested in actual photographs, and not in some non-existent (in fact, impossible, as we shall now see) ideal type of images. Photographs as we know them are definitely not "ideal" in 
Scruton's sense (on this point, of course, Scruton is right). Look again at Figs. 4.1 and 4.2, and examine closely the way any photograph is produced. Let us focus on the case of digital photography. First, light goes through a lens and hits a sensor; this gives rise to a RAW file which is a recording of the way photons hit the photodetectors constituting the sensor's surface. ${ }^{1}$ The RAW file is not yet a photograph-it needs to be interpreted/converted in order to become an image, that is, an image we can see anything on (or in). In the case of an automatic point-and-shoot digital camera, this step is usually done by a piece of software built-in the camera which has been programmed in a certain way in order to convert the RAW file into an image file that can then be printed or viewed on a computer monitor. In the case of more sophisticated cameras (typically, DSLRs), this automatic treatment of RAW files can be deactivated and can be postponed - one can copy the RAW file on a computer and only then manually convert the RAW file into an image file.

Once we keep in mind the way digital photographs are produced, it then becomes simply obvious that digital manipulation is an unavoidable, necessary, and essential step in their process of production. Without digital manipulation, there would simply be no photographs. Photons hitting the camera's sensor produce electrical inputs, which have to be "tampered with" in order to produce any picture at all. An important point to note here is that these digital manipulation steps are not purely mechanical and purely causal conversions of electrical inputs into image files; rather, they are steps where decisions have to be taken - at the very least, these include decisions about exposure, brightness, contrast, and white balance. As we have seen, these decisions can either be taken by the photographer who manually works on her RAW files, or they can be automatized, which means that they are taken not by the photographer herself but by the team of engineers who programmed the camera's built-in software. But one way or another, we easily see here that the steps that lead to a creation of a digital photograph include, as a matter of necessity, digital manipulation where decisions have to be taken. This is of course not the end of the story, but at least a first rough version of the claim I want to defend is established: in principle, not only digitally manipulated pictures count as photographs, but digital manipulation is in fact a necessary step in the process of production of digital photographs.

This situation is entirely similar to the case of traditional film photography, where some of the steps in the process of production include necessary chemical and other manipulation (when using a developer, a stop bath, a fixer, and an enlarger), where human intervention is as essential as it is in the case of digital photography (decisions are taken about exposure, brightness, contrast, colour, and other in a way which is technologically different from digital photography but in principle very similar). There is, however, a significant difference between digital photography and traditional film photography, which I already mentioned above but which requires a more detailed discussion: the easiness with which digital photographs can be digitally altered and variously manipulated (either manually, or in an automatized way, or both). As we have seen above, digital manipulation which includes a photographer's

\footnotetext{
${ }^{1}$ This is of course only a very simplified explanation.
} 
intentional decisions is by necessity part of a process of production of any photograph. But the way this is done, and the amount and type of these manipulations makes a crucial difference. In the next section I shall focus on this issue.

$\S 2$. To start with, there is a general claim I want to make: there is no principled reason to "privilege" digital manipulations done using a software that is built in a camera's body to digital manipulations done using a software installed on a computer - it would simply be entirely arbitrary to do so. A digital camera's body is equipped with a processor and a piece of software that manipulates RAW files in order to produce image files, either in a fully automatized way where all decisions have been taken by somebody else than the photographer herself, or in a more or less manual way, where the photographer herself can program the settings of her camera's software to adjust the way RAW files will be converted into image files-typically, these settings include at the very least exposure, brightness, contrast, saturation, and white balance (but they can also include much more striking adjustments, for instance in order to produce a photograph with a sepia effect, directly from the RAW file). The claim I want to make now is that there is no principled difference between this way of digitally manipulating one's photographs using the built-in software, and taking the RAW file out of the camera, copying it on a computer, and doing these adjustments later on a computer. (Note that even in this way of doing things, it is still open whether these manipulations are done manually, by the photographer herself, or automatically, by the programmers of the software installed on the computer.) A consequence of this claim, which I wish to fully endorse, is that a photographic system, that is, the device that is used to produce photographs, is not only composed of a camera and of components which are spatially located inside the camera's body; rather, it is a whole composed of many different components which can, of course, all be spatially located inside a camera's body, but there is no reason why they would have to be so. Indeed, in the case mentioned above, the photographic system is composed of a lens, a body, a processor, and a software (I am simplifying here, of course) where some of these components are located inside the camera's body and other are located inside a computer. Thus the various components of a photographic system can be spatially scattered, as well as, obviously, temporally scattered (since it can be a long time after a RAW file has been created that it is converted into an image file). None of this, I believe, is very controversial and unfamiliar to the traditional film photographer. On the contrary, traditional photographic systems using film are almost never entirely located inside a camera's body (with the notable exception of Polaroid cameras and similar): a dark room with all of its components is necessary to produce a photograph.

To sum up my starting points: as a matter of necessity, digital photographs are always digitally manipulated, either by the photographer herself or by somebody else; these manipulations require intentional decisions; and they can be implemented using tools located inside a camera's body or using a computer. This now connects with one of our initial questions, since we see here that there is no reason in principle to reject digitally modified photographs as being photographs, including photographs that have been "tampered with" on a computer. But not only is this not the end of the story, it's actually here that things start to get messy and conceptually difficult. 


\subsection{Vague Limits}

$\S 1$. Indeed, given all we have seen until now, it will then be very difficult to find clear criteria for discriminating digital manipulations (retouches) that will be allowed to be part of a process of production of photographs and those that will not-any such attempts take the risk of raising worries of arbitrariness. One may be tempted to adopt two extreme attitudes to 'solve' this problem. Firstly, one could want to claim that no retouches are acceptable, but this would be simply false, since as we have seen a minimal amount of digital manipulation is necessary in order to produce any photograph at all. One then may wish to adopt the opposite stance and claim that any kind or amount of retouching is to be accepted. As a principled solution to avoid the arbitrariness worry, this will of course do, but such an attitude seems to strain the limits of credibility: think, for instance, of a photograph of the Eiffel Tower in Paris, but where the RAW file has been digitally altered so much that the resulting image is just a flat vivid green surface - it would seem difficult, to say the least, to count such an image as a photograph of the Eiffel Tower, or indeed as a photograph at all.

$\S 2$. The problem here is a problem of vagueness: there is a limit to the type and amount of retouches that a digital photograph can be altered with while still remaining a photograph, but it is a vague, under-determined, and indeterminate one. What we know here, following my considerations in the preceding sections, is that the question is not whether digital manipulation is acceptable; rather the question is about how much of it can be accepted. Thus, we understand here the nature of this limit, but it is not an easy task to determinately say which it is.

It might help to consider some examples of borderline cases of digital images which lie at the very limit between photographs and something else (as before, high resolution colour versions can be found here: https://www.jiribenovsky.org/thelimits ofart).

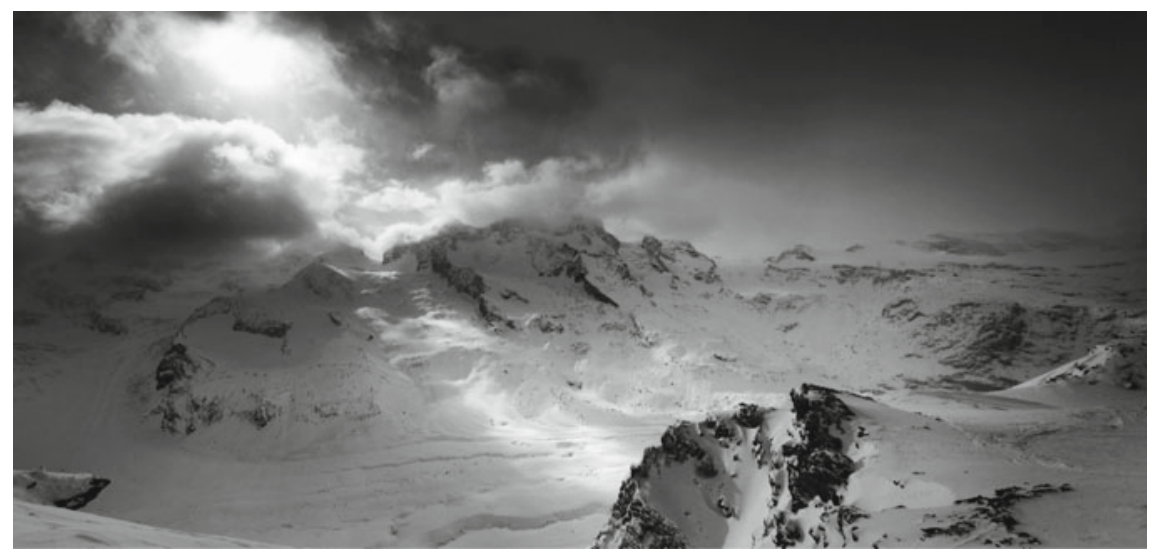

Image 3 


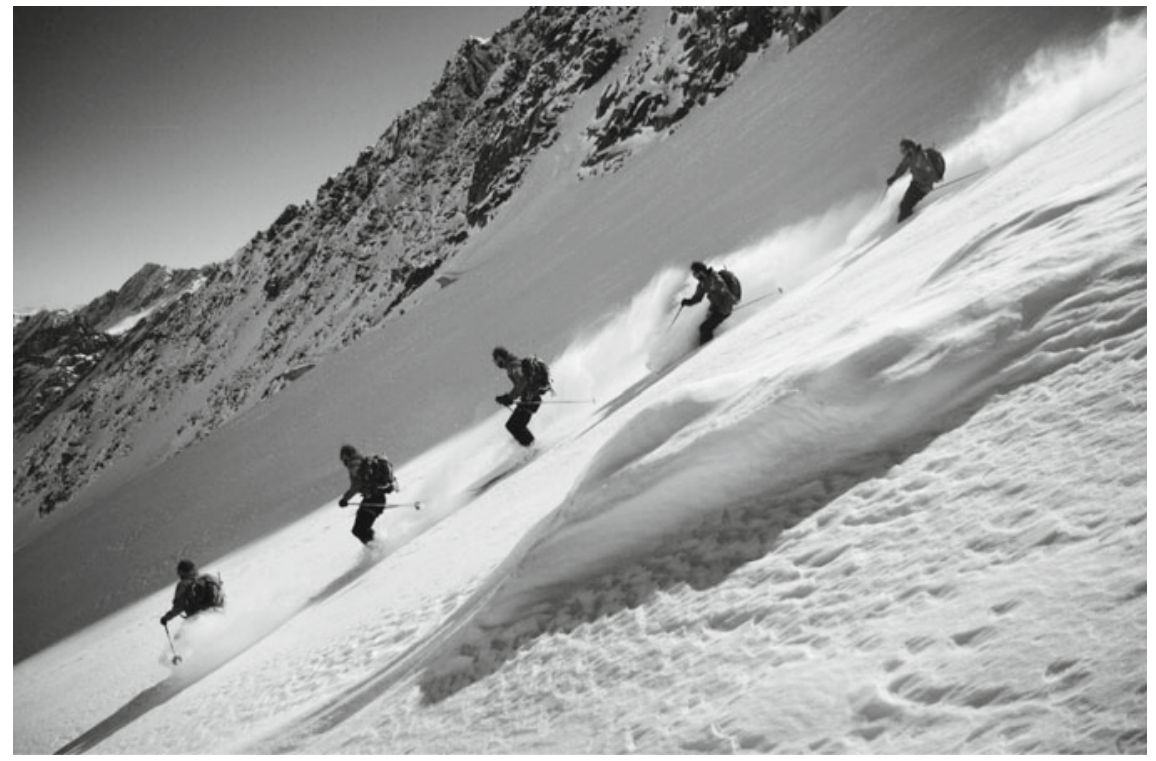

Image 4

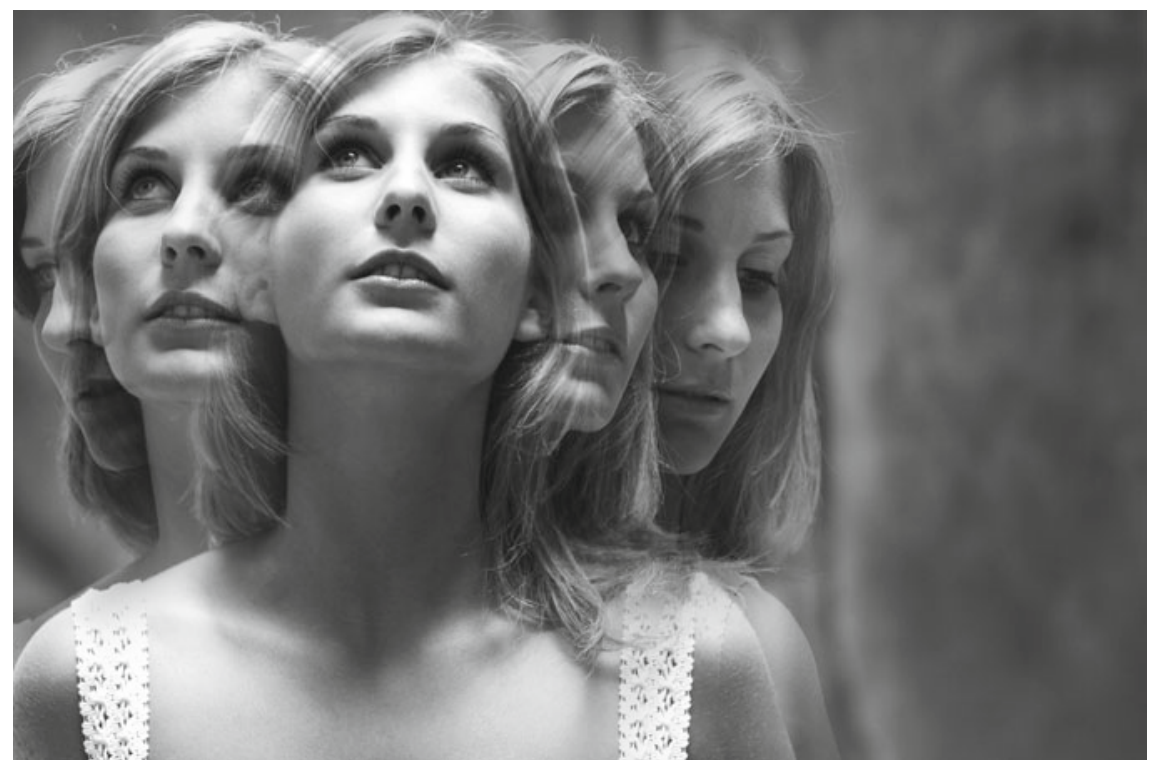

Image 5 


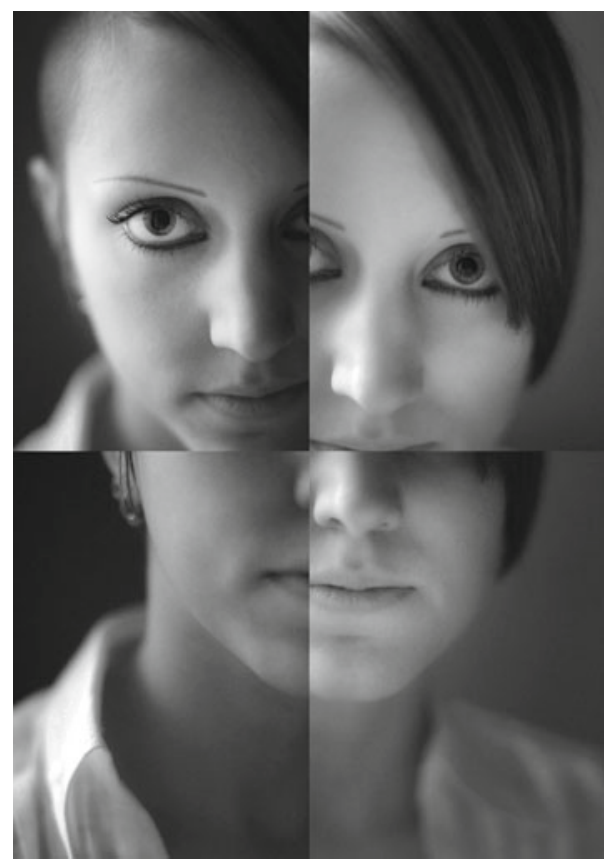

Image 6

As a first gut reaction, one might be tempted to disqualify Images 4,5 , and 6 as being photographs, since they are clearly composed of several more-or-less continuous and more-or-less digitally manipulated pictures, but clearly accept Image 3 as being a photograph since it is 'just' one simple image of a landscape. If this is an intuition one has, it then tells us something interesting which puts us on the right track towards understanding somewhat better where the limit between photographs and non-photographs lies, since in fact Image 3 has been produced by using several photographs as well (more, actually, than in the case of Images 4, 5, and 6). Here is a screen capture of a production stage of Image 3: 


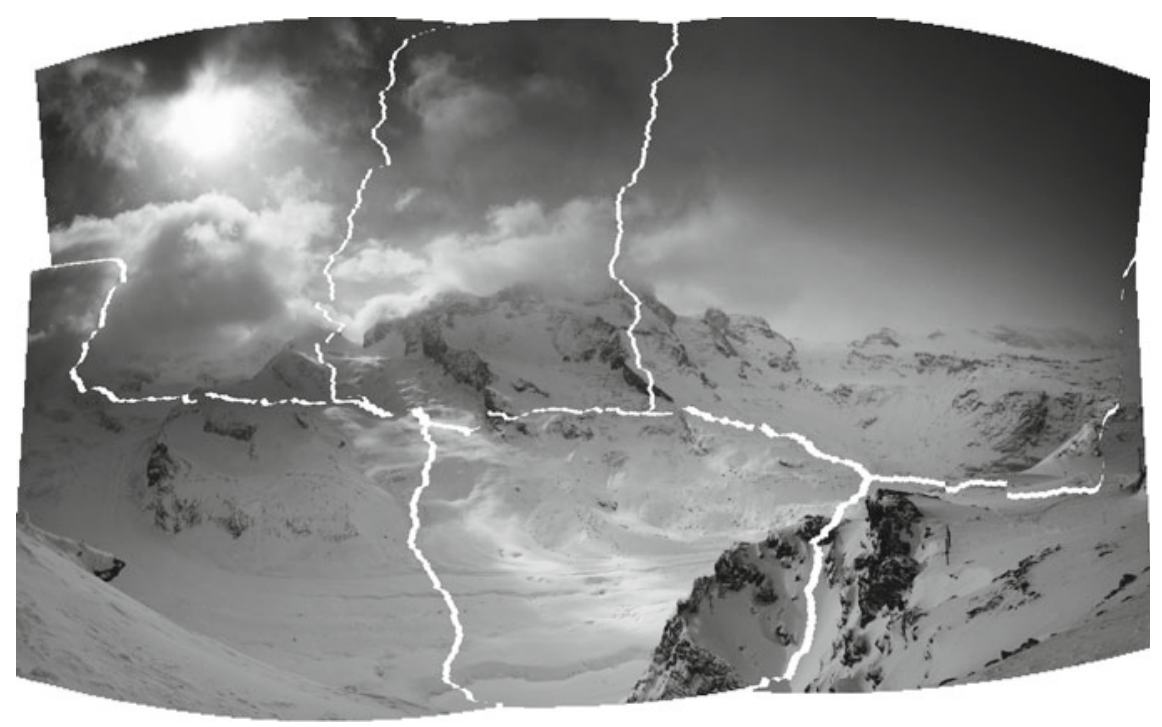

Image 7

The interesting thing to note about the above-mentioned intuition is that, often, if one has it, then one accepts Image 3 as being a photograph only until one learns about the way it was produced (see Image 7). What is at stake here is to decide whether the reason to accept (or not) digital pictures such as Images 3, 4, 5, and 6 as being photographs lies in what we see in the resulting image (which is something we see) or rather in the way the image was produced (which is something we believe/know).

If one were to take the latter option, one might want to claim that none of the Images above counts as a photograph since, somewhat trivially, there are several photographs there, and not one. If, on the other hand, one prefers the first option, then one might want to follow the above-mentioned intuition and claim that Image 3 is a photograph, while, say, Image 6 clearly is not, but one may have doubts about Images 4 and 5 since, while these images have been created in Photoshop by a superposition of several different photographs, such a type of images can also be obtained in traditional film photography by using a multiple exposure techniquethis where the "other option" sneaks in again. What the instability of this kind of intuitions shows is that our concept of what counts as a photograph is such that it a result of both considerations about what we see (on the resulting image) and what we believe (about the way it was created).

$\S 3$. This, of course, does not help us to 'solve' the vagueness problem by identifying a clear limit between photographs and non-photographs, but, I want to submit, it helps us to understand its nature. (Note that our puzzle behaves here as most puzzles concerning genuine cases of vagueness do: typically, they do not have such a kind of 'solution'; for instance, there just is no way to determine precisely, without arbitrariness, a limit between "being bald" and "not being bald", or between "being a heap" and "not being a heap"- - even epistemicist accounts of vagueness which claim that 
there is such a precise limit take it to be unknowable. ${ }^{2}$ ) In order to deepen our understanding of the nature of this limit, I shall focus below on the case of photographs produced by Light Field cameras, which is such that it creates photographs which can be re-focused after they have been taken. But before I do so, a detour is necessary in order to grasp another essential feature of the nature of photographs - this will be the job of the Sect. 4.4

\subsection{The Process of Production and Necessary Decisions}

$\S 1$. Let us examine the process of production of photographs from a different angle. As already mentioned, it has been widely argued that the process of production is the core of the nature of photographs (both digital and traditional), and that it sets photographs apart from other types of images, like paintings, because photographs are the only images produced in a way which is purely mechanical, causally closed, and which does not include human intervention. Thus, Bazin (1960, p. 7) famously claims photography to be "[...] a mechanical reproduction in the making of which man plays no part" and adds that "For the first time, between the originating object and its reproduction there intervenes only the instrumentality of a nonliving agent. For the first time an image of the world is formed automatically, without the creative intervention of man." Hopkins (2012) defends, in his own (different) way, a similar claim as well: "[...] photography, in contrast [with hand-made pictures], involves a causal chain free from the influence of people's beliefs and experiences [...]." Similar claims have also, for very different reasons, been endorsed by Roger Scruton (see Scruton 1981) and Kendall Walton (whose motivation was to defend his famous transparency thesis about photographs: "Objects cause their photographs and the visual experiences of viewers mechanically; so we see the objects through the photographs. By contrast, objects cause paintings not mechanically but in a more 'human' way, a way involving the artist; so we don't see through paintings" (Walton 1984, p. 261).

There are many important, interesting, and true claims in the neighbourhood of these quotations, and many of them I do share with their authors (for instance, Walton's transparency thesis strikes me as correct, for independent reasons). But we have already seen that taken at face value these claims about the allegedly purely mechanical way in which photographs are produced without human intervention are simply false, because at least some human decisions are necessary parts of the process of production of photographs (both digital and traditional). I shall now focus on another type of such decisions, which will make salient another important and essential feature of the nature of photographs.

$\S 2$. The kind of intentional decisions we have seen until now included only decisions that take place at 'later' stages of the process of production-that is, after the shutter has been pressed. But there are crucial decisions that a photographer has to

\footnotetext{
${ }^{2}$ Williamson (1994) contains probably the most famous and influential epistemicist account. My own version of an epistemicist view is to be found in Benovsky (2011b).
} 
take before pressing the shutter as well, including at least aperture, shutter speed, and focal length, but typically also framing (composition), focus, white balance, and other. All of these, or at the very least the first three, are decisions which have to be taken, since no photograph can be made without specifying these settings. As before, they can be taken either by the photographer herself, or-in the case of an automatic camera - by somebody else who programmed the camera's built-in software (which happens even in the peculiar case where a camera unintentionally "takes a photograph" itself when, say, it falls on the floor and the shutter is thus accidentally pressed-I shall not focus on this type of cases in what follows, but at least in the case of digital cameras, decisions taken by the programmers do play here their role in the same way they do when a Sunday snapshooter takes a picture in the camera's automatic mode). Now, an important feature of this type of decision I want to emphasize is that they appeal to tools that a skilled photographer can use to guide and direct the attention of the spectator of her photograph, in order to convey a message, a thought, an idea. Elsewhere, ${ }^{3}$ I discuss this way the photographer interacts with her audience in detail; here it will be sufficient to take one quick example to illustrate my point. Consider aperture: all things being equal, the wider the aperture, the shallower the depth of field. Thus decisions about the aperture setting will have an effect on the depth of field which in turn will have an effect of what is sharp and what is blurred on the resulting photograph. This is one of the central tools that a photographer has at her disposal to convey a message with her photograph-in short, by making some elements on her picture to be sharper than their environment, she can tell the spectators of her photograph: "Look here, this is what I wanted to show you, this is important". What the photographer does here is that she exploits the natural tendency of our perceptual system to be attracted by what is sharp rather than by what is blurred, and she can thus 'force' the look of the spectator of her image to focus on some elements of her photograph rather than on others - and use this technique to 'tell a story' with her photograph, rather than 'only' depict the world in a sort of 'documentary' way. Here is an example of a mistake I once made that illustrates the point: when climbing the Matterhorn with a mountain guide, he asked me when we reached the summit to take a nice portrait photograph of him standing on the top, that he wished to use for his Curriculum Vitae and his advertisement brochures. I took the photograph using a telephoto lens $(320 \mathrm{~mm})$ at $\mathrm{f} / 2.8$ (wide aperture), which resulted in a portrait of his face with a nicely blurred background - the kind of photograph that valorises the person's face, by making it stand out from its environment and by attracting the attention of the spectator's look to it (see the "attention management" technique above), thus making it a central element of the kind of visual message the photograph conveys. The mistake, of course, was that on such a type of photograph, with such a shallow depth of field, one could not see in the resulting image that we were at 4'478 m above sea level on a famous summit in the Alps-the photograph could have been taken more or less anywhere with the same result, it was not even obvious that we were in the mountains at all! The choice of a wide aperture was thus here totally inappropriate since it 'masked' the kind of message the photograph was

\footnotetext{
${ }^{3}$ Benovsky (2012).
} 
supposed to convey, namely, a picture of a mountain guide high in the mountains on a famous summit. Luckily, the guide immediately spotted the mistake and we were able to correct it, by taking another photograph using a f/6.3 aperture (i.e. a wider depth of field, resulting in a less blurred background). What this mistake and the way it was corrected shows is how a photographer can convey one type of message ("look, here is a beautiful face!") rather than another ("look, here is a face of a person in such-and-such an environment!") using different aperture settings. Again, I have over-simplified the whole chain of reasoning here (see Benovsky 2012 for a detailed account) but it should be sufficient to appreciate the point(s) I want to make: as a matter of necessity, there are human decisions that must be taken in order to produce a photograph concerning at the very least aperture, shutter speed, and focal length; these decisions allow the photographer to manipulate and manage the attention of the spectator by exploiting our natural perceptual tendencies, which in turn allows her to 'tell a story' with her photograph and to convey a message in a very clear (nonmetaphorical) sense. These decisions being necessary (since no photograph can be made without taking them), not only we see here again that the claim about a 'purely mechanical' way photographs are allegedly produced 'without human intervention' is false, but we also learn about another essential feature of photographs: they are ways for the photographer to control the attention of the spectator and to convey a message. In short, photographs not only have depictive powers but narrative powers as well.

(In the case of a Sunday snapshooter, who does not take decisions about aperture herself, she still takes crucial and story-telling decisions when she frames, composes, and focuses her photograph in one way rather than another, namely at least the decisions about the relative size and position of the main subject as compared to its environment, thus again making it more salient and more important (or notdepending on the kind of message she wishes to convey with her photograph)).

$\S 3$. Light Field cameras exhibit a technology which challenges deeply the way photographers work, and which constitutes a fascinating borderline case of an image which is such that it is unclear whether it is a photograph or not. (For an example of images produced by a Light Field Camera (LFC) follow the link here: https://www. jiribenovsky.org/thelimitsofart).

As you can see, for obvious reasons, it is not possible, as in the case of my other examples reprinted above, to produce a print of a LFC-image since, contrary to all types of photographs we are accustomed to, it is a 'moving picture'-more precisely, it is not a static image. Indeed, LFC-images are such that they can be refocused after they have been taken; moreover, they can be refocused by the spectator of the image, and not by the photographer.

All this, I submit, makes LFC-images not photographs at all. Let me elaborate. We have seen in the preceding section how a photographer can use the tools at her disposal to guide and control the look of the spectator of her photograph and convey a message. With a LFC, this is not possible anymore: the resulting images are such that it is not possible for the photographer to control what is sharp and what is blurred on the photograph, it is not possible to control where the spectator will focus her attention, and thus LFCs deprive the photographer of her best and strongest tool for 
communicating with her audience-it deprives photographs of their narrative powers. Thus, LFC-images lack one essential features photographs have. Photographs are essentially static images, and since LFC-images are not, they must be something else than photographs. But they are not like cinema either, interestingly, for the very same reason: as Carroll (2008, chap. 5) has shown, the motion picture maker does a job which is similar to the photographer's in the sense that she controls and guides the attention of the spectator of her movie, typically, by taking decisions about depth of field, about the order in which one sees things, about for how long one sees them, about the relative size (scale) of the main subject, and so on. Cinema thus shares with photography this essential feature: they are both ways for an artist to 'force' her audience to perceive the world which is depicted in a way she wants to show it (and this is how both cinema and photography have narrative powers). LFC-images are very different in this respect, since they are dynamic 'unsettled' images which are at least partly (but importantly!) under the control of the spectator, and not of the artist. LFC-images are thus not photographs, they are not cinema, they are digital sculptures. Indeed, the way the artist interacts here with her audience is very similar to the way a sculptor does. When observing a sculpture, one can focus on different parts of it in one's own way, in one's own order, and for as long as one wishes-a sculpture, contrary to a photograph, does not 'force' one's look to focus on some parts of it rather than others. One can choose the angle from which one looks at a sculpture. The way a spectator interacts with a sculpture thus gives rise to a dynamic experience of it. LFC-images thus lie outside the vague boundaries of what counts as a photograph and what does not.

\subsection{Photographs, Paintings, Vagueness}

$\S 1$. In the preceding sections, we have seen various ways in which the process of production of photographs contains essential steps that characterize the nature of photography_which can help us to decide what counts as a photograph and what does not. Inter alia, I have offered reasons to reject the view that this process is such that photographs are produced in a 'purely mechanical' way, by showing how human intervention is an essential part of the process. But there is one very good motivation behind the 'mechanicist claim', one which I think is important to preserve, in order to have a good grasp on what counts as a photograph and what does not, namely, the claim that a photograph is always a photograph of something that exists (which makes it a different type of picture, in principle, than a painting). To my mind, this is correct. But there is a threat of losing this claim, if one believes, as I do and as I have argued above, that digital manipulation and digital retouches should be accepted as parts of a normal process of production of photographs, and consequently that sometimes even heavily retouched images should still count as photographs- there is the risk that such a picture does not depict anything existing any more. 
$\S 2$. There are two claims I made that can help to avoid this unwelcome result. Firstly, and very importantly, while it is true that photographs depict always something existing, they always do so not in some sort of 'ideally objective' and purely causal way but rather they show us the world in a way the photographer wants us to see $i t$. This, as we have seen, applies to photography in general, and not only to digitally manipulated photographs; just think of all the types of necessary human interventions that are part of the process of production of a photograph (necessary digital manipulations, and the photographer's necessary decisions). As a consequence, a photograph depicts always that something exists, but not necessarily (never, actually) how it is. A photograph that has been digitally manipulated can thus still count as a photograph, and still be an image that depicts something that exists, while depicting it in a way which is different from the way it is. (Again, this claim applies to photography in general, and not only to the case of digital manipulation.)

Secondly, I have insisted on the inescapable vagueness of the limit between what counts as a photograph and what does not. I have also insisted on the fact that we cannot determine, once and for all, where this limit lies-such is its vague nature. But the claim cherished by the friends of the mechanicist thesis, which I share, gives us a little more grasp on the whereabouts of this limit: once the resulting image does not depict anything existing anymore, it ceases to be a photograph. This criterion thus gives us one way of specifying the 'upper boundary' of the fuzzy and vague zone containing borderline cases of photographs. Thus, very heavily digitally retouched photographs do not count; rather, they become digital paintings. The limit between (digital) paintings and photographs is a vague one.

$\S 3$. In this Chapter, I tried to make some progress concerning the issue about what counts as a photograph and what does not, with the purpose of finding some essential features of photography in the process of doing so. Among the essential features of photographs I raised the following: they always depict something that exists, but not always how it is; both what we see in the resulting image and the way the image was produced count in determining whether it is a photograph or not; the process of production is not purely mechanical and causally closed, on the contrary, it involves many steps where human decisions have to be taken; they are static images which have 'narrative powers', that is, which the photographer can use to control and guide the attention of the spectator; digital photographs are photographs, and digital manipulation is perfectly acceptable as a part of a normal process of their production, at least to some extent; importantly, the limit between what counts as a photograph and what does not is irreducibly vague. Without discussing it here, I also quickly mentioned Walton's transparency claim which I think is correct (even if not always for Walton's reasons; see Benovsky 2011a). To be sure, the photograph has not yet disclosed all its secrets, and, as future technologies will arrive and incessantly change the ways it can be produced and manipulated, many new and interesting insights lie ahead, modifying our understanding of what the limits between photographs and (digital) paintings are. 


\section{References}

Bazin A (1960) The ontology of the photographic image. transl. by Hugh Gray. Film Q 13:4

Benovsky J (2011a) Three kinds of realism about photographs. J Speculative Philos 25:4

Benovsky J (2011b) Vagueness: a statistical epistemicist approach. Teorema XXX/3

Benovsky J (2012) Photographic representation and depiction of temporal extension. Inquiry 55(2):194-213

Carroll N (2008) The philosophy of motion pictures. Blackwell Publishing, Malden

Hopkins R (2012) Factive pictorial experience: What's special about photographs? Noûs 46(4):709_ 731

Scruton R (1981) Photography and representation. Critical Inq 7:3

Walton KL (1984) On the nature of photographic realism. Crit Inq 11:2

Williamson T (1994) Vagueness. Routledge

Open Access This chapter is licensed under the terms of the Creative Commons Attribution 4.0 International License (http://creativecommons.org/licenses/by/4.0/), which permits use, sharing, adaptation, distribution and reproduction in any medium or format, as long as you give appropriate credit to the original author(s) and the source, provide a link to the Creative Commons license and indicate if changes were made.

The images or other third party material in this chapter are included in the chapter's Creative Commons license, unless indicated otherwise in a credit line to the material. If material is not included in the chapter's Creative Commons license and your intended use is not permitted by statutory regulation or exceeds the permitted use, you will need to obtain permission directly from the copyright holder.

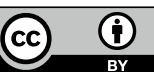

